05

\title{
Структура, генерационные характеристики и фотостабильность новых гетерил-кумаринов
}

\author{
(C) С.С. Ануфрик, С.Н. Анучин, В.В. Тарковский \\ Гродненский государственный университет им. Янки Купалы, \\ 230023 Гродно, Республика Беларусь \\ e-mail: anufrick@grsu.by
}

Поступила в редакцию 03.04.2020 г.

В окончательной редакции 12.05.2020 г.

Принята к публикации 07.07.2020 г.

В условииях наносекундной когерентной накачки излучением электроразрядного эксимерного ХеСl-лазера, а также микросекундного лазерного возбуждения лазером-преобразователем на красителях и ламповой накачки исследован ряд 7-диэтиламинокумаринов, содержащих в положении 3 кумаринового ядра различные объемные заместители - гетероциклические радикалы. Установлена их роль и арильного фрагмента в структуре молекулы кумарина на спектральные и генерационные характеристики новых кумаринов. Экспериментально показано, что триазольный и оксадиазольный гетероциклы являются предпочтительными с точки зрения улучшения генерационной способности и фотоустойчивости исходных соединений. Модификация структуры молекул исходного 7-диэтиламино- и юлолидинкумаринов присоединением в положении 3 объемных гетероциклических радикалов позволила получить новые лазерные среды, генерирующие излучение в спектральном диапазоне 490-560 nm, обладающие достаточно высокой генерационной эффективностью и фотоустойчивостью при различных условиях возбуждения.

Ключевые слова: кумариновые красители, 7-диэтиламинокумарины, гетероциклические радикалы, спектральные и генерационные характеристики, юлолидинкумарины.

DOI: $10.21883 /$ OS.2020.12.50326.127-20

Одной из важных проблем, сдерживающих широкое практическое применение лазеров на красителях (ЛК), являются их недостаточно высокие генерационные характеристики, обусловленные фотораспадом органических молекул, и как следствие - недостаточный ресурс работы активных сред данного класса. Особенно это актуально для ЛК с ламповой накачкой, где в излучении накачки присутствует достаточно жесткое УФ излучение. При когерентной накачке фотораспад играет существенную роль при использовании в качестве источников возбуждения лазеров, излучающих в УФ области спектра [1-8]. Под воздействием излучения накачки органические молекулы участвуют в фотохимических реакциях, в результате которых образуются обратимые и необратимые фотопродукты, вносящие потери в области усиления активной среды. Указанные процессы в значительной степени ограничивают возможности создания и ресурс работы высокоэффективных жидкостных и твердотельных активных сред перестраиваемых лазеров на красителях.

В связи с вышесказанным актуальной задачей является поиск новых генерирующих красителей, обладающих повышенной эффективностью и фотостойкостью. Анализ литературных источников показывает, что наиболее перспективными соединениями в сине-зеленой области спектра являются красители кумаринового класса [9-13]. Данные красители характеризуются достаточной генерационной эффективностью как при лазерной, так и ламповой накачке. Они перекрывают генерируемым излучением спектральный диапазон 450-500 nm. При этом актуальным является поиск новых лазерных соединений для области спектра $500-560 \mathrm{~nm}$. Известные красители перекрывают данный спектральный диапазон лишь частично и характеризуются весьма низкой эффективностью генерации [10]. Существует достаточно много работ, посвященных вопросам фотостабильности и повышению ресурса работы лазерных красителей при воздействии мощного УФ излучения накачки [14-18]. Так, в [14] показано, что уменьшение КПД генерации для соединений, генерирующих в области $400 \mathrm{~nm}$, связано с внутримолекулярными фотофизическими процессами при увеличении длительности и плотности мощности импульсов накачки эксимерного лазера. В [15] отмечается, что фотостабильность указанных сред сильно зависит от интенсивности и длительности импульсов накачки, так как эти параметры влияют на соотношение выходов промежуточных необратимых фотопродуктов. Фотостабильность молекул органических красителей зависит также и от других факторов. Авторами работы [16] показано, что при мощной когерентной накачке существенное влияние оказывает формирование усиленной суперлюминесценции. В $[17,18]$ предлагается метод анализа фотофизических процессов, позволяющий оценить энергию электронных состояний, силы осцилляторов электронных переходов, поляризации излучения и другие параметры.

Исследование генерационной эффективности и фотостабильности кумариновых красителей в настоящей ра- 


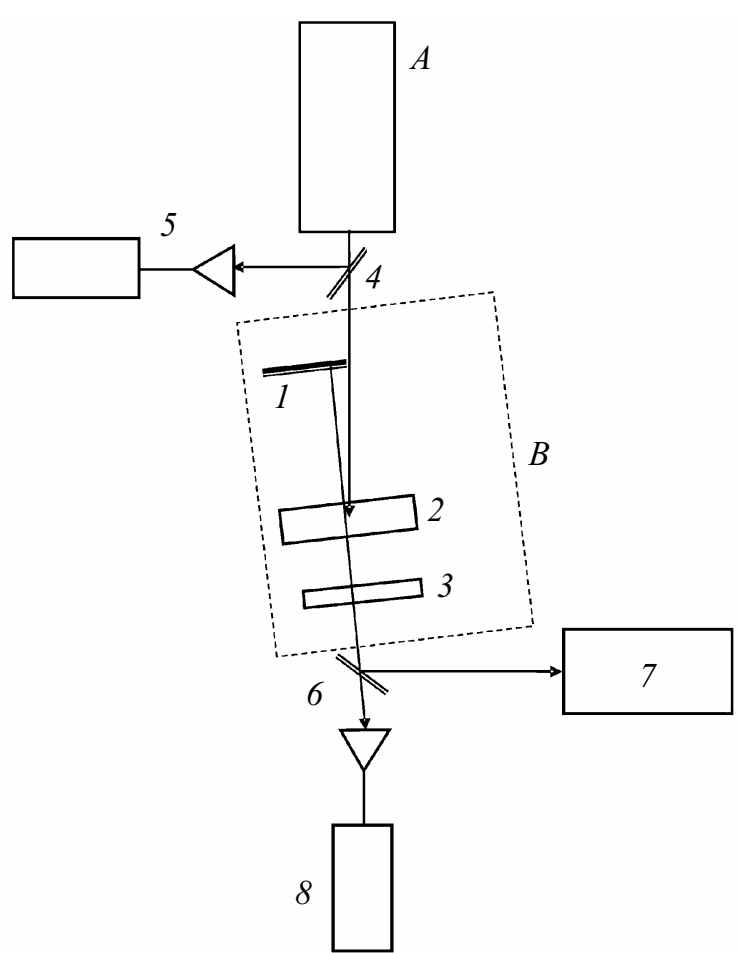

Pис. 1. Схема экспериментальной установки: $A$ - лазер накачки (на красителях с ламповым возбуждением или электроразрядный $\mathrm{XeCl}$-лазер); $B$ - лазер на красителях (лазерпреобразователь): 1 - „глухое“ зеркало резонатора лазера на красителях, 2 - кювета с красителем, 3 - выходное зеркало лазера на красителях, 4,6- стеклянные поворотные пластинки, 5,8 - измерители энергии, 7 - дифракционный спектрограф.

боте проводилось в условииях наносекундной когерентной накачки излучением электроразрядного эксимерного ХеCl-лазера, микросекундного лазерного возбуждения лазером-преобразователем на красителях и ламповой накачки. Схема экспериментальной установки представлена на рис. 1. Энергия излучения (генерации) возбуждающего эксимерного ХеCl-лазера равнялась $200 \mathrm{~mJ}$ при длительности импульса $60 \mathrm{~ns}$. Излучение накачки фокусировалось цилиндрической линзой $(f=10 \mathrm{~cm})$ и направлялось по квазипродольной схеме в кювету с этанольным раствором исследуемого красителя. Резонатор ЛК с базой $L=15 \mathrm{~cm}$ был образован плоским зеркалом с коэффициентами отражения $R_{1} \sim 100 \%$ и выходным зеркалом с оптимальным коэффициентом отражения $R_{2} \sim 30$ и $60 \%$ (в зависимости от вида накачки). В качестве источника микросекундной когерентной накачки использовался ЛК на основе коаксиальной лампы-кюветы с внутренним диаметром $8 \mathrm{~mm}$ и длиной $250 \mathrm{~mm}$. Эта же лампа-кювета применялась для исследования кумариновых соединений на фотостойкость (ламповое возбуждение). Длительность светового импульса накачки по уровню 0.5 составляла $2 \mu$ s при фронте нарастания $0.8 \mu \mathrm{s}$. Электрическая энергия возбуждающего импульса равнялась 300 J. Концентрация исследуемых сое- динений в этанольных растворах была оптимальной для каждого вида возбуждения. При когерентном лазерном возбуждении она равнялась $\sim 10^{-3} \mathrm{~mol} / \mathrm{l}$, а для ламповой накачки $\sim 10^{-4} \mathrm{~mol} / \mathrm{l}$.

Измерение энергии генерации ЛК и контроль энергии накачки осуществлялись измерителями ИМО-2Н. Спектр широкополосной генерации регистрировался спектрографом ДФС-8 или СТЭ-1 со световодной транспортировкой излучения.

В табл. 1 представлен ряд 7-диэтиламинокумаринов (7-ДАК), содержащих в положении 3 кумаринового ядра различные объемные заместители - гетероциклические радикалы. В таблице указаны названия соединений, структурные формулы, длины волн максимумов поглощения $\left(\lambda_{\mathrm{abs}}^{\max }\right)$ и флуоресценции $\left(\lambda_{\mathrm{flu}}^{\max }\right)$ выход флуоресценции $\left(\eta_{\mathrm{flu}}\right)$, энергия генерации $\left(E_{\mathrm{gen}}\right)$ при ламповой накачке, КПД генерации при лазерном возбуждении (Eff), спектральный диапазон генерации $\left(\Delta \lambda_{\text {gen }}\right)$.

Сравнение спектрально-люминесцентных и генерационных характеристик данных соединений проводилось в зависимости от молекулярной структуры заместителя в последовательности от незамещенного 7-ДАК до соединений, содержащих триазольный, оксадиазольный и тиазольный гетероциклы. Пятичленные гетероциклы с одним гетероатомом и двумя двойными C-С-связями соответствуют требованиям ароматичности. Ядра гетероциклов представляют собой плоский цикл с сопряженной системой электронных орбиталей, которая включает $4 n+2 p$-электронов, два из которых поставляет гетероатом. Атом азота „Пиррольного“ типа существует в $s p^{2}$-гибридном состоянии и образует три $\sigma$-связи: две с углеродом, одну с водородом или заместителем. $\sigma$-связи сформированы за счет гибридных орбиталей, тогда как неподеленная электронная пара занимает негибридную $p$-орбиталь, что делает ее способной к сопряжению с углерод-углеродными $\pi$-связями кумаринового ядра. Таким образом, гетероатом азота предоставляет циклической $\pi$-электронной системе два электрона. В совокупности с четырьмя электронами атомов углерода образуется ароматический секстет ВЗМО. Исследуемые гетероциклические радикалы объединяет тот факт, что число $\pi$-электронов на высшей занятой молекулярной орбитали (ВЗМО) превышает число атомов в кольце, в связи с чем они являются $\pi$-избыточными [15].

Как видно из таблицы, присоединение триазольного гетероцикла с 4-фенильной группой (соединение № 1) в положении 3 к 7-ДАК приводит к резкому батохромному сдвигу максимумов спектра поглощения (на $52 \mathrm{~nm}$ ) и спектра флуоресценции (на $24 \mathrm{~nm}$ ). При этом стоксов сдвиг между спектрами поглощения и флуоресценции сократился на $28 \mathrm{~nm}$, что не отразилось на квантовом выходе флуоресценции, который равнялся 70\%. Энергия генерации данного соединения возросла в 1.5 раза (до $2 \mathrm{~J}$ ), а спектр генерации сместился в зеленую область на $40 \mathrm{~nm}$. Сокращение стоксова сдвига привело к расположению спектра генерации на длинноволновом 
Таблица 1. Спектральные и генерационные характеристики производных 7-ДАК

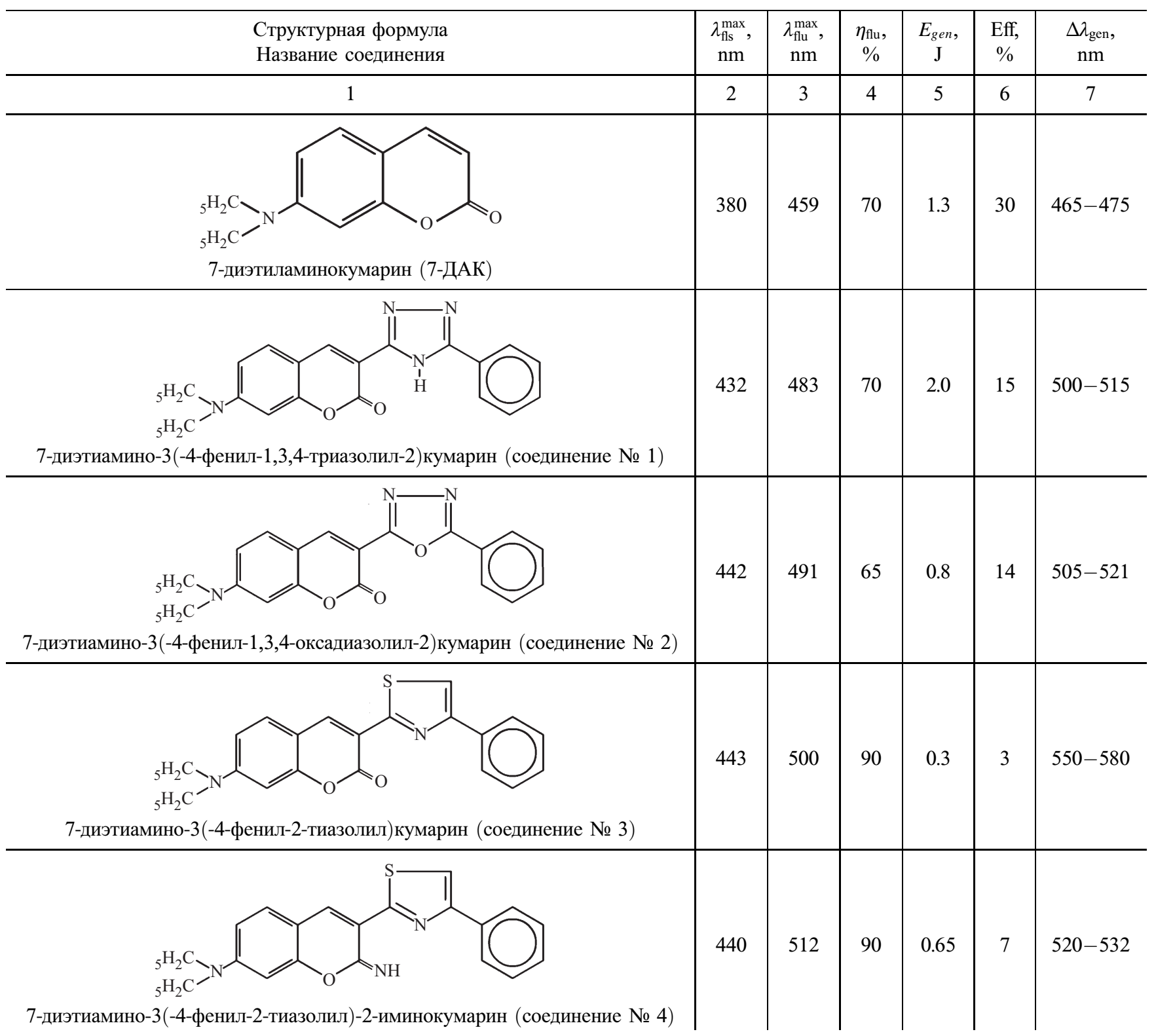

крыле спектра флуоресценции. Характерно, что при возбуждении эксимерным лазером КПД генерации уменьшился в 2 раза (с 32 до 15\%). Причиной этому может являться высокая плотность мощности УФ излучения накачки $(\sim 2 \mathrm{MW})$, приводящая, возможно, к разрыву связи или к фотораспаду объемного гетероцикла и появлению дополнительных потерь.

Значительный длинноволновый сдвиг спектров поглощения и флуоресценции при присоединении 4-фенилтриазолил радикала к кумариновому ядру обусловлен удлинением цепи сопряжения молекулы, как уже отмечалось, появлением дополнительных $\boldsymbol{\pi}$-электронов и соответственно усилением их осцилляции при возбуждении. Наличие сильного электронно-акцепторного заместителя в положении 3 и донорной диэтиламиногруппы в положении 7 кумаринового ядра изменяет цепь сопряжения молекулы по сравнению с незамещенным 7-ДАК, где электронно-акцепторной является карбонильная группа в положение 2. Локализация отрицательного заряда на гетероциклическом радикале и положительного на диэтиламиногруппе кумарина приводит к возрастанию дипольного момента молекулы и соответственно усилению осцилляции $\pi$-электронов по новой цепи сопряжения при возбуждении.

Замена 4-фенил-триазольного гетероцикла на 4-фенил-оксадиазольный в положении 3 кумаринового ядра (соединение № 2) сопровождается дальнейшим, но не столь значительным батохромным смещением спектров поглощения на $10 \mathrm{~nm}$ и флуоресценции на $8 \mathrm{~nm}$. Квантовый выход флуоресценции снизился на 5\%, а энергия 
генерации уменьшилась более чем в 2 раза $(0.8 \mathrm{~J})$ по сравнению с соединением № 1. При когерентном возбуждении, однако, КПД генерации практически не изменился. Снижение энергии генерации при ламповой накачке может быть связано с меньшей фотоустойчивостью оксадиазольного радикала. Длинноволновое смещение спектров поглощения и флуоресценции соединения № 2 по сравнению с соединением № 1, вероятно, обусловлено большей электроотрицательностью оксадиазольного радикала из-за наличия в структуре гетероцикла кислорода. Атомы кислорода и серы, как и атом азота, способны выступать в качестве донора неподеленной пары электронов, дополняя ароматический электронный секстет ВЗМО молекулы. Следует отметить, что в молекулах с гетероатомом кислорода и серы не образуется третьей $\sigma$-связи, но имеется дополнительная неподеленная электронная пара. Эта пара электронов, находящаяся на гибридной орбитали, очевидно, не может вступить в сопряжение с $\pi$-системой ядра ввиду того, что $s p^{2}$-орбиталь ориентирована перпендикулярно по отношению к р-орбиталям.

Переход к соединению № 3, содержащему 4-фенил-2-тиазолил радикал, не отразился на положении спектра поглощения, но максимум спектра флуоресценции сместился батохромно на $9 \mathrm{~nm}$, и квантовый выход флуоресценции возрос до 70\%. При этом энергия генерации снизилась до уровня порога, а КПД генерации составил несколько процентов $(\sim 3 \%)$. Как видно, квантовый выход флуоресценции не коррелирует с эффективностью генерации. Слабая генерационная эффективность данного соединения обусловлена, вероятно, наличием атома серы в пятичленном гетероцикле.

При этом важную роль играет электроотрицательность серы, находящейся в составе цикла. При переходе от атома азота к сере, а затем к кислороду донорный мезомерный эффект гетероатома ослабевает, а индуктивный акцепторный - возрастает, в результате чего изменяется направление дипольного момента, подтвержденное экспериментально [15].

Измененение структуры молекулы соединения № 3 путем замены карбонильной группы на иминогруппу (соединение № 4) в положении 2 кумаринового ядра привело к незначительному коротковолновому сдвигу максимума спектра поглощения $(\sim 3 \mathrm{~nm})$ и батохромному смещению максимума спектра флуоресценции на $12 \mathrm{~nm}$. Квантовый выход флуоресценции увеличился до $80 \%$, а энергия и КПД генерации возросли вдвое до $0.7 \mathrm{~J}$ и $7 \%$ соответственно. При этом спектр генерации тиазолил иминокумарина расположен в области $520-560 \mathrm{~nm}$, что соответствует смещению максимума спектра на $70 \mathrm{~nm}$ по сравнению с незамещенным 7-диэтиламинокумарином.

Далее проведено сравнение спектральных и генерационных характеристик новых гетерил-кумаринов с ядром юлолидина. Стабилизация структуры кумариновой основы ядром юлолидина 7- $\mathrm{N}\left(\mathrm{CH}_{2}\right)_{6}$ обеспечивает более жесткую планарную структуру молекулы. Это привело к значительному возрастанию разности дипольных моментов молекулы в основном и возбужденном состояниях, и как следствие, к уменьшению вероятностей внутренней и интеркомбинационной (ИК) конверсий [15].

Результаты исследования представлены в табл. 2. В качестве эталонного соединения выбран 3-карбамоил-2-иминоюлолиднкумарин, который в настоящее время является наиболее эффективным и фотостабильным лазерным красителем, генерирующим излучение в зеленой области спектра. Высокая генерационная эффективность и фотоустойчивость 3-карбамоил-2-иминоюлолидинкумарина обусловлена конформационной стабильностью молекулы, ее большей ароматичностью и меньшей вероятностью внутренней и ИК конверсий.

Как видно, замена карбамоильной группы на 4-фенил-триазольный гетероцикл в положении 3 молекулы кумарина (соединение № $1^{\prime}$ ) приводит к синхронному длинноволновому сдвигу спектров поглощения и флуоресценции на $30 \mathrm{~nm}$. Квантовый выход флуоресценции возрос до 90\%. При этом энергия при ламповом возбуждении и КПД генерации (лазерная накачка) практически не изменились и составили $2.0 \mathrm{~J}$ и $15 \%$ соответственно. Спектр генерации этого соединения расположен в области 530-560 nm. Переход к соединению № $2^{\prime}$, содержащему оксадиазольный гетероцикл, сопровождается значительным снижением энергии генерации (более чем в 3 раза) и КПД. Спектр генерации при этом сместился гипсохромно на $20 \mathrm{~nm}$ и соответствует области генерации эталонного соединения. Снижение генерационной эффективности и соответственно коротковолновый сдвиг спектра генерации свидетельствуют о возрастании наведенных потерь. В частности, как будет показано далее, о появлении дополнительного поглощения в спектральной области 530-560 nm, обусловленного, вероятно, продуктами фотораспада оксадиазольного гетероцикла из-за наличия в структуре сильного акцептора - кислорода.

Для соединения № 3', содержащего 4-фенил-2-тиазольный радикал, наблюдается дальнейшее батохромное смещение спектров поглощения и флуоресценции на $10 \mathrm{~nm}$ по сравнению с соединением № $2^{\prime}$. Длинноволновое смещение спектров однозначно обусловлено заменой оксадиазольного на тиазольный гетероцикл (аналогично 7-ДАК). При этом наблюдается значительное снижение энергии генерации (до 0.4J), а КПД при лазерном возбуждении составил $\sim 6 \%$. Как уже отмечалось, причиной низкой генерационной эффективности данного соединения может являться наличие серы в пятичленном гетероцикле. Как известно, сера является элементом третьего периода. Валентный угол C-S-C в тиазольном гетероцикле близок к $90^{\circ}$, что не характерно для $s p^{2}$-гибридного атома в пятичленном цикле (обычно он равен $108^{\circ}$ для тиофена) [15].

Согласно литературным данным [15], атом серы почти не гибридизован, и $\sigma$ - и $\pi$-связи образованы чистыми $p$-орбиталями. В соответствии с альтернативной версией в образовании связей $\mathrm{C}-\mathrm{S}$ принимают участие 
Таблица 2. Спектральные и генерационные характеристики производных юлолидинкумарина

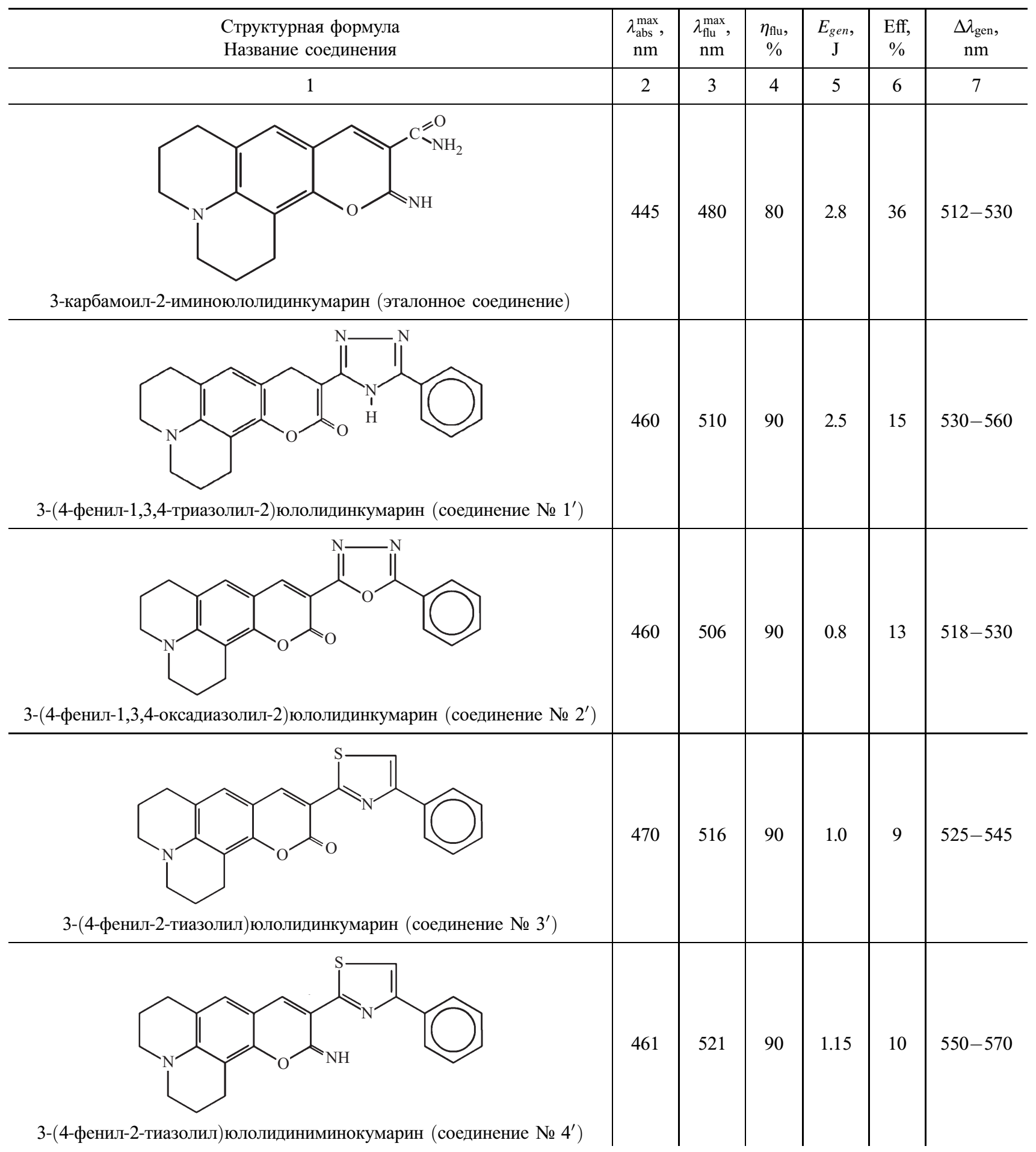

$d$-орбитали атома серы, что отражается на пространственной конфигурации тиазольного гетероцикла.

Характерно, что замена карбонильной группы на иминогруппу в положении 3 тиазолилюлолидинкумарина (соединение № 4', табл. 2) привела к противоположному синхронному смещению спектров поглощения и флуоресценци: спектр поглощения сместился гипсохромно на $5 \mathrm{~nm}$, а спектр флуоресценции - батохромно также на $5 \mathrm{~nm}$. При этом квантовый выход флуоресценции сохранился на уровне $90 \%$, а энергия генерации и КПД возросли вдвое. Положительное влияние иминогруппы в структуре молекулы может быть обусловлено ее хорошими элетронно-акцепторными свойствами, что проявляется также в более высокой генерационной 
эффективности эталонного соединения (3-карбамоил2-иминоюлолидинкумарин).

Для объяснения различий в энергии и КПД генерации гетерил-кумариновых соединений далее исследовалась их фотоустойчивость при лазерном и ламповом возбуждениях.

Зависимость энергии генерации гетерил-кумаринов от количества облучений в лампе-кювете приведена на рис. 2. Как видно из рисунка, для всех исследованных соединений 10-кратное облучение приводит к снижению энергии генерации в два раза, что соответствует $3 \mathrm{~kJ}$ вложенной электрической энергии. Дальнейший ход зависимостей является более плавным, монотонным, и для различных соединений после 30-60 импульсов облучения наблюдается срыв генерации.

Характерно, что наибольшей фотостойкостью в условиях ламповой накачки среди 7-ДАК обладают соединения, содержащие в положении 3 кумаринового ядра триазольный и оксадиазольный гетероциклы (соединения № 1 и № 2). При этом они характеризуются более высокой эффективностью генерации. Краситель 3-(4-фенил-2-тиазолил)юлолидинкумарин (соединение № $3^{\prime}$ ) с тиазольным гетероциклом (рис. 2, кривая 4) имеет меньшую начальную энергию генерации, но по фотоустойчивости сравним с эталонным соединением, что объясняется наличием ядра юлолидина в структуре данной молекулы и специфическими свойствами атома серы в гетероцикле. Сравнение кривых на рис. 2 показывает, что данные кумариновые соединения обладают более высокой фотохимической стойкостью, чем родамин $6 \mathrm{G}$ (кривая 5). Так, если у новых соединений генерационная способность в лазере с ламповой накачкой сохраняется после 30-50 импульсов возбуждения, то для родамина $6 \mathrm{G}$ она исчезает уже после 3-5 импульсов возбуждения [17].

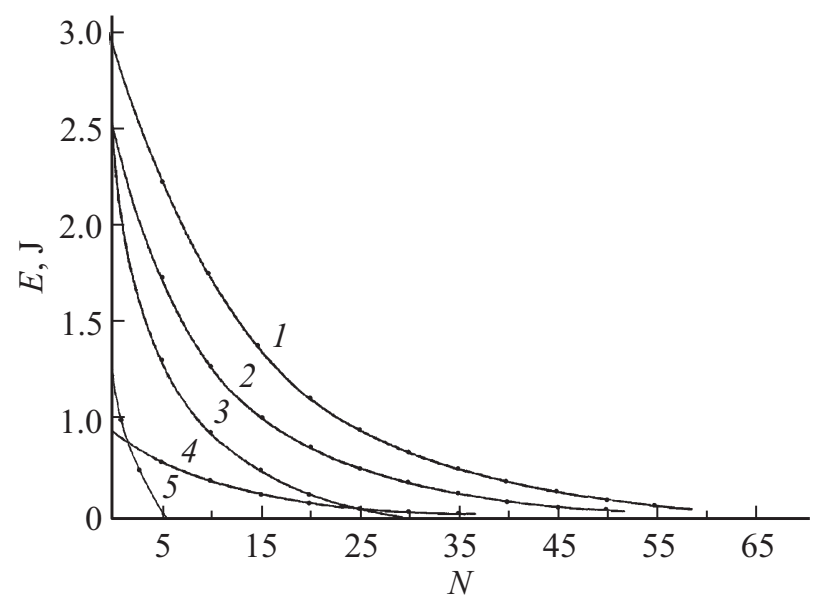

Рис. 2. Зависимость энергии генерации новых гетерилкумаринов от количества $N$ импульсов облучения в коаксиальной лампе-кювете: 1 - „эталонный“ кумарин, 2 - соединение № 1,3 - соединение № $2,4-$ соединение № $3^{\prime}, 5-$ родамин $6 \mathrm{G}$.

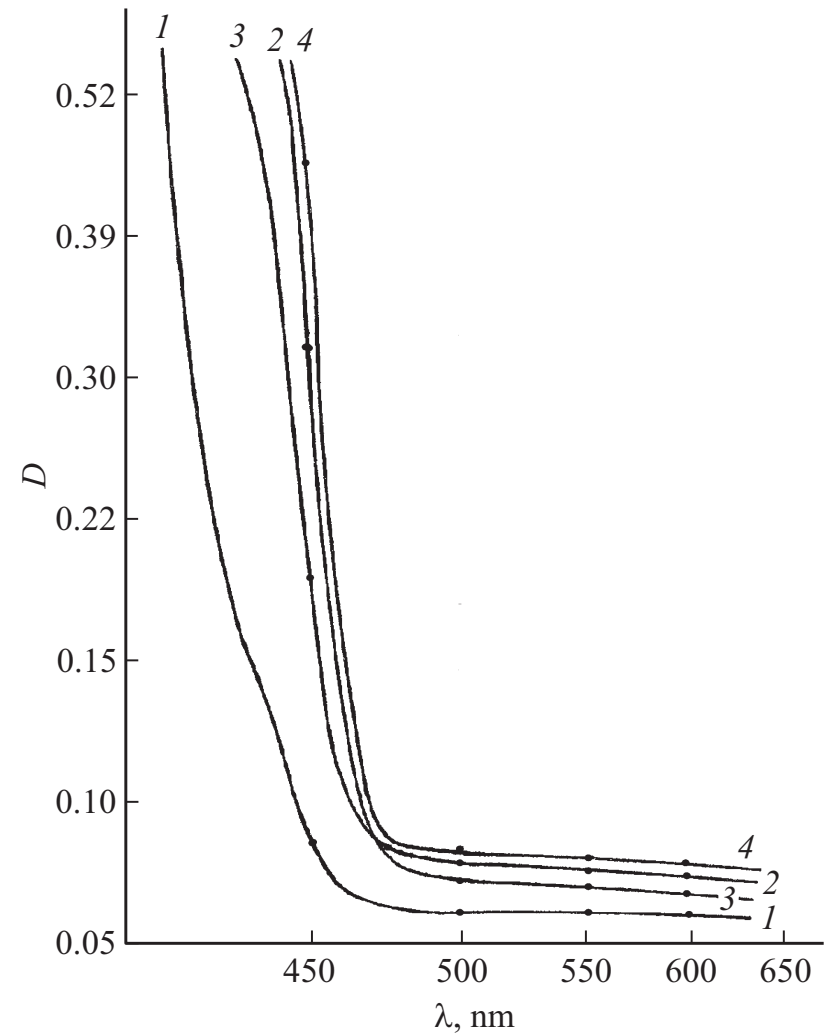

Рис. 3. Зависимость оптической плотности $D$ в области генерации раствора 3-карбамоил-2-иминоюлолидинкумарина после облучения: 1 - необлученный раствор, 2 - облученный излучением эксимерного ХеCl-лазера, 3 - облученный в лампе-кювете, 4 - облученный ХеСl-лазером и в лампекювете.

Для выяснения причины падения генерационной эффективности далее исследовалась зависимость оптической плотности растворов исследуемых соединений от количества облучений в условиях лазерной и ламповой накачки. На рис. 3 приведено изменение оптической плотности в области длинноволнового склона полосы флуоресценции и области генерации „эталонного“ соединения (3-карбамоил-2-иминоюлолидинкумарин) после облучения в коаксиальной лампе-кювете и излучением ХеCl-лазера. Как видно из рис. 3, в спектральной области генерации эталонного соединения наблюдается прирост оптической плотности $(\Delta D)$ при всех видах облучения. Наибольшее значение $\Delta D=0.04$ по сравнению с необлученным раствором наблюдается при возбуждении эксимерным лазером и ламповой накачке.

При возбуждении ХеСl-лазером длинноволновая полоса поглощения эталонного соединения сместилась батохромно на $\sim 20 \mathrm{~nm}$ (рис. 3), при этом прирост оптической плотности по сравнению с необлученным раствором составил $\sim 30 \%$. В результате максимум спектра генерации сместился также на $15 \mathrm{~nm}$ с 530 до $545 \mathrm{~nm}$ без снижения эффективности генерации. 
Характер зависимости оптической плотности облученных растворов гетерил-кумаринов от длины волны различается (рис. 4). Как и для эталонного соединения, для облученных растворов красителей наблюдаются различия на длинноволновом склоне полосы флуоресценции, связанные, вероятно, с образованием продуктов фотораспада и появлением наведенного поглощения. Характерным для всех исследованных соединений является прирост оптической плотности в спектральной области генерации.

Прирост оптической плотности $(\Delta D)$ в спектральной области генерации облученных соединений представлен в табл. 3. Как видно, для 7-ДАК с триазольным гетероциклом прирост оптической плотности в области генерации практически совпадает с эталонным соединением (незамещённый 7-ДАК, $\Delta D \sim 13 \cdot 10^{-3}$ ). Среди изученных соединений наименьшие значение $\Delta D=(4-8) \cdot 10^{-3}$ наблюдается для 7-диэтилюлолидинкумаринов, содержащих триазольный и оксадиазольный гетероциклические радикалы, что отражается на их большей энергии генерации.

Прирост оптической плотности и уширение спектра поглощения в длинноволновой области могут свидетельствовать о том, что основной причиной химических и фотохимических превращений молекул кумаринов может являться процесс размыкания пиронового кольца. При переходе молекулы гетерил-кумарина в

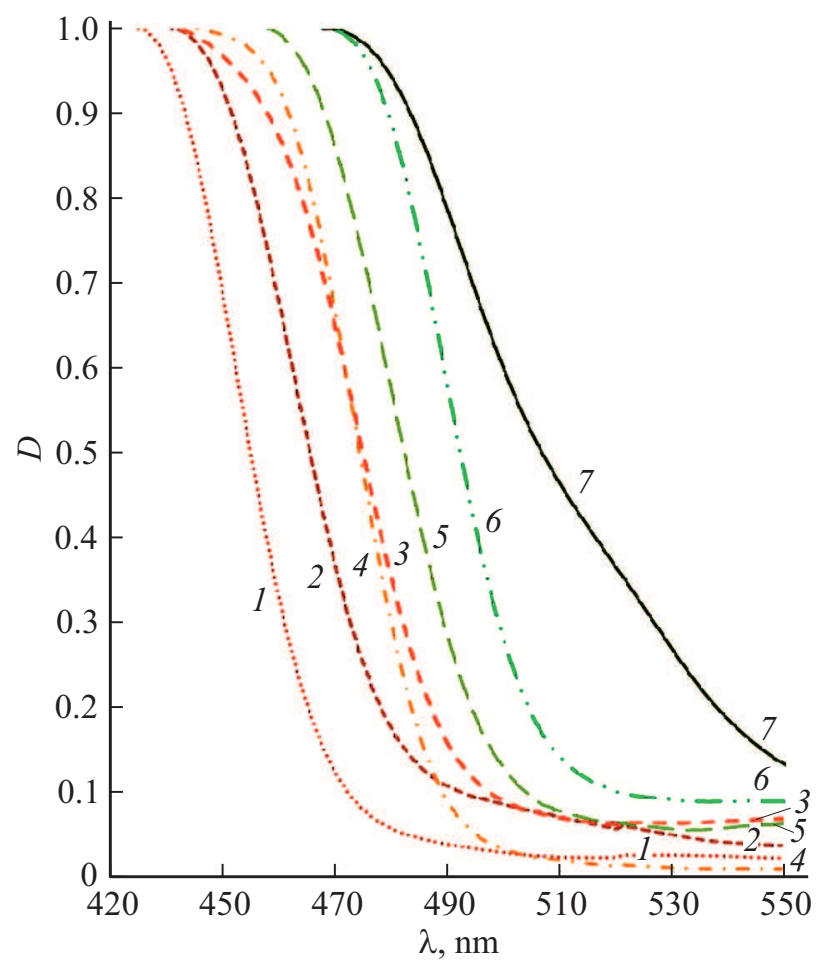

Pис. 4. Зависимость оптической плотности от длины волны в области генерации облучённых гетерил-кумаринов: 1 соединение № 1, 2 - соединение № 2, 3 - соединение № 3, 4 - соединение № 4, 5 - соединение № $2^{\prime}, 6$ - соединение № $3^{\prime}, 7$ - соединение № $4^{\prime}$.

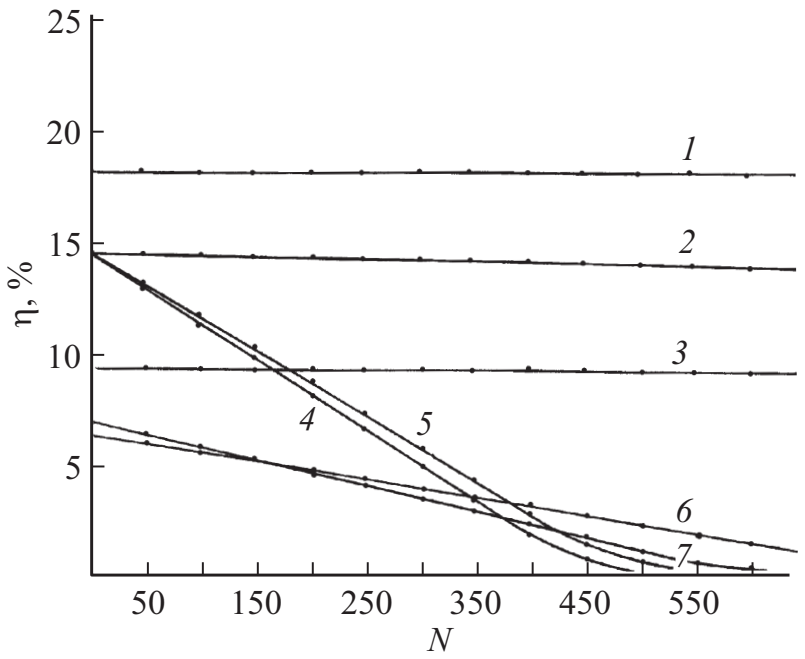

Рис. 5. Зависимость КПД генерации гетерил-кумаринов от количества облучений импульсами микросекундной (1-3), наносекундной (4-7) длительности: 1 - „эталонный“ кумарин; 2,5 - соединение № 1; 3,4 - соединение № 2 ; 6 соединение № 4'; 7 - соединение № 3.

возбужденное состояние размыкание пиронового кольца приводит к перераспределению $\pi$-электронной плотности в цепи сопряжения кумаринового ядра и остатка гетероциклического радикала, обусловленного разрывом связей $-\mathrm{C}-\mathrm{N}-\mathrm{C}-,-\mathrm{C}-\mathrm{O}-\mathrm{C}-$ и $-\mathrm{C}-\mathrm{S}-\mathrm{C}-$ в пятичленном гетероцикле. Эти процессы сопровождаются ростом вероятности безызлучательных переходов, резким падением квантового выхода флуоресценции и эффективности генерации [18].

Как видно из таблицы, наибольший прирост оптической плотности в ряду замещённых 7-ДАК наблюдается для окса- и тиазолил-производных кумарина (соединения № $2-\Delta D=62 \cdot 10^{-3}$ и № $\left.4-\Delta D=46 \cdot 10^{-3}\right)$. Для юлолидинкумаринов с данными заместителями прирост оптической плотности значительно меньше (соединения № $2^{\prime}-\Delta D=4 \cdot 10^{-3}$ и № $4^{\prime}-\Delta D=18 \cdot 10^{-3}$ ), что и подтверждается их большей фотоустойчивостью.

На рис. 5 приведена зависимость КПД генерации гетерил-кумаринов от количества импульсов облучения когерентным излучением наносекундной и микросекундной (ЛК на красителях) длительности. Как видно из рисунка, при когерентной микросекундной накачке наибольшей фотостойкостью обладают 7-диэтил-юлолидинкумарины, содержащие триазольный гетероцикл, а значительно меньшей фотоустойчивостью характеризуются производные 7-ДАК, содержащие в положении 3 окса- и тиазольный радикалы.

Снижение генерационной эффективности 7-диэтиамино-3(-4-фенил-1,3,4-триазолил-2)кумарина (соединение № 1) в зависимости от вида и количества импульсов возбуждения представлено на рис. 6. Как видно из рисунка, эффективность генерации соединения № 1 при микросекундном возбуждении практически не снижает- 
Таблица 3. Изменение оптической плотности $(\Delta D)$ в спектральной области генерации облученных гетерил-кумаринов

\begin{tabular}{|c|c|c|c|}
\hline Название соединения & $\Delta D \cdot 10^{3}$ & Название соединения & $\Delta D \cdot 10^{3}$ \\
\hline 7-диэтиламинокумарин (незамещённый 7-ДАК) & 10 & $\begin{array}{c}\text { 3-карбамоил-2-иминоюлолидинкумарин } \\
\text { (эталонное соединение) }\end{array}$ & 4 \\
\hline $\begin{array}{c}\text { 7-диэтиамино-3(-4-фенил-1,3,4-триазолил-2)кумарин } \\
\text { (соединение № 1) }\end{array}$ & 13 & $\begin{array}{c}\text { 3-(4-фенил-1,3,4-триазолил- } \\
\text { 2)юлолидинкумарин } \\
\text { (соединение № } 1^{\prime} \text { ) }\end{array}$ & 8 \\
\hline $\begin{array}{l}\text { 7-диэтиамино-3(-4-фенил-1,3,4-оксадиазолил- } \\
\text { 2)кумарин (соединение № 2) }\end{array}$ & 62 & $\begin{array}{c}\text { 3-(4-фенил-1,3,4-оксадиазолил- } \\
\text { 2)юлолидинкумарин } \\
\left.\text { (соединение № } 2^{\prime}\right)\end{array}$ & 4 \\
\hline $\begin{array}{c}\text { 7-диэтиамино-3(-4-фенил-2-тиазолил)кумарин } \\
\text { (соединение № 3) }\end{array}$ & -42 & $\begin{array}{l}\text { 3-(4-фенил-2-тиазолил)юлолидинкумарин } \\
\left.\text { (соединение № } 3^{\prime}\right)\end{array}$ & 34 \\
\hline $\begin{array}{c}\text { 7-диэтиамино-3(-4-фенил-2-тиазолил)-2-иминокумарин } \\
\text { (соединение № 4) }\end{array}$ & 46 & $\begin{array}{c}\text { 3-(4-фенил-2-тиазолил)юлолидиниминокумарин } \\
\left.\text { (соединение № } 4^{\prime}\right)\end{array}$ & 18 \\
\hline
\end{tabular}

Примечание. Облучение этанольных растворов красителей объемом $30 \mathrm{~cm}^{3}$ производилось излучением ртутной лампы высокого давления мощностью $250 \mathrm{~W}$ в течение $1 \mathrm{~h}$.

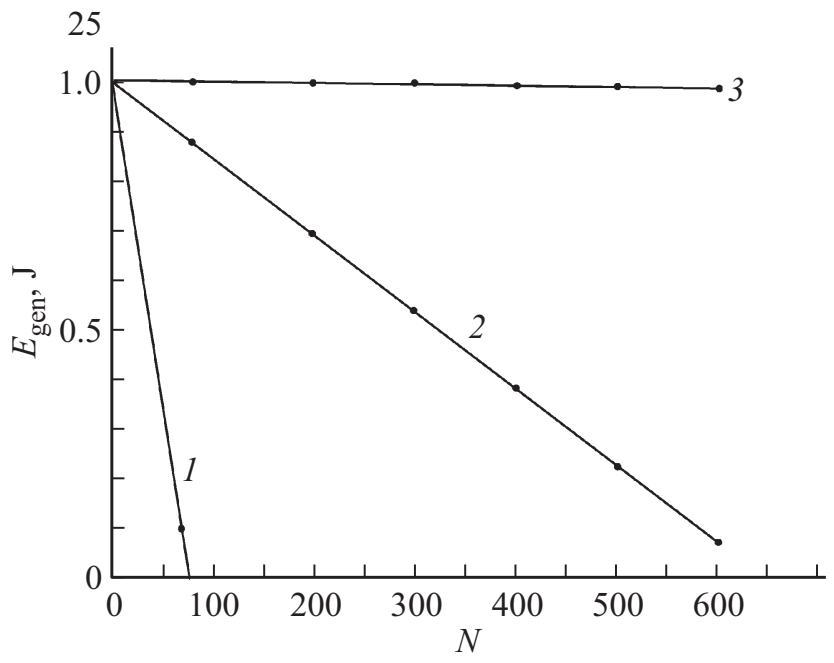

Рис. 6. Зависимость энергии генерации соединения № 1 от количества импульсов облучения при ламповой (1), нано- (2) и микросекундной (3) накачках.

ся (кривая 3). При ламповой накачке генерационная способность данного соединения утрачивается после 80 импульсов облучения (кривая 1), а при наносекундном возбуждении (кривая 2) ресурс работы составляет уже более 650 импульсов облучения. Дальнейшие исследования показали, что эффективность генерации при микросекундной накачке эталонного соединения и соединений № 1 и № 2 не прекращалась после $2 \cdot 10^{3}$ импульсов, что соответствует поглощённой световой энергии $300 \mathrm{~J}$.

Стабильность генерации при микросекундном возбуждении объясняется максимальным согласованием спектров генерации красителя в лазере накачки со спектром поглощения красителя в лазере-преобразователе. Кроме того, в излучении накачки отсутствует УФ составляю- щая, приводящая к интенсивному фотохимическому распаду красителя [18].

Установлена роль гетероциклических радикалов и арильного фрагмента в структуре молекулы кумарина во влиянии на спектральные и генерационные характеристики новых кумаринов. Экспериментально показано, что триазольный и оксадиазольный гетероциклы являются предпочтительными с точки зрения улучшения генерационной способности и фотоустойчивости исходных соединений. Модификация структуры молекул исходного 7-диэтиламино- и юлолидинкумаринов присоединением в положении 3 объемных гетероциклических радикалов позволила получить новые лазерные среды, генерирующие излучение в спектральном диапазоне 490-560 nm, обладающие достаточно высокой генерационной эффективностью и фотоустойчивостью при различных условиях возбуждения.

Таким образом, на примере исследованных гетерилкумариновых соединений показана возможность получения новых генерирующих сред, обладающих высокой фотохимической устойчивостью и энергетической эффективностью.

\section{Список литературы}

[1] Методы расчета оптических квантовых генераторов. Т. 2 / Под ред. Б.И. Степанова. Минск: Наука и техника, 1968. $655 \mathrm{c}$.

[2] Теренин А.Н. Фотоника молекул красителей и родственных органических соединений. Л.: Наука, 1967. 616 с.

[3] Лазеры на красителях / Под ред. Ф.П. Шефера. М.: Мир , 1976. $329 \mathrm{c}$.

[4] Magde D., Gaffney T., Campbell B.T. // IEEE J. Quant. Electron. QE-17. 1981. P. 489.

[5] Кричевский Г.Е. Фотохимические превращения красителей и светостабилизация окрашенных материалов. М.: Химия, 1986. 248 с. 
[6] Bernhardt A.F., Herbst R.L., Kronick M.N. // Laser Focus.1982. V. 18. P. 59.

[7] Дзюбенко М.И., Маслов В.В., Науменко И.Г., Пелипенко В.П. // Опт. и спектр. 1980. Т. 49. № 4. С. 764-767.

[8] Борисевич Н.А., Грузинский В.В., Палтарак Н.М., Петрович П.И. // ЖПС. 1970. Т. 12. № 5. С. 926-929.

[9] Мостовников В.А., Рубинов А.Н., Анубрик С.С., Гиневич Г.Р., Никитченко В.М., Водотыка Г.С. // ЖПС. 1977. T. 27. C. 59.

[10] Дзюбенко М.И., Водотыко Г.С., Маслов В.В., Никитченко В.М. // Опт. и спектр. 1975. Т. 39. С. 554.

[11] Дзюбенко М.И., Маслов В.В., Науменко И.Г., Никитченко В.М., Пелипенко В.П. // Опт. и спектр. 1978. Т. 45. C. 814.

[12] Кузнецова Р.Т., Копылова Т.Н., Дегтлренко К.М., Майер Г.В., Сергеев А.К., Нестеренко С.Н., Афанасьев С.Б., Верескун В.Н. // Квант. электрон. 1996. Т. 23. № 9. С. $797-$ 800.

[13] Анубрик С.С., Тарковский В.В., Сазонко Г.Г., Асимов М.М. // ЖПС. 2012. Т. 77. № 5. С. 695.

[14] Копылова Т.Н., Светличный В.А., Майер Г.В., Резниченко А.В., Подгаецкий В.М., Пономарева О.В., Самсонова Л.Г., Филинов Д.Н., Помогаев В.А., Тельминов Е.Н., Лапин И.Н., Светличная Н.Н., Синченко Е.И. // Квант. электрон. 2003. Т. 33. № 11. С. 967-974.

[15] Нейланд О.Я. Органическая химия. М.: Высшая школа, 1990. $751 \mathrm{c}$.

[16] Кузнецова Р.Т., Копылова Т.Н., Майер Г.В., Самсонова Л.Г., Светличный В.А., Васильев А.В., Филинов Д.Н., Тельминов Е.Н., Каботаева Н.С., Сваровская Н.В., Подгаецкий В.М., Резниченко А.В. // Квант. электрон. 2004. T. 34. № 2. C. 139-146.

[17] Батище С.А., Мостовников В.А., Тарковский В.В. // Квант. электрон. 1995. Т. 22. № 7. С. 651-652.

[18] Мостовников В.А., Гиневич Г.Р., Анубрик С.С., Шалимо А.Л. // ДАН БССР. 1979. Т. 23. С. 921. 